\title{
Exploring Engineering Faculty Experiences with COPUS: Strategies for Im- proving Student Learning
}

\section{Dr. Tareq Daher, University of Nebraska, Lincoln}

Tareq Daher earned his Bachelors in Computer Science from Mutah University in Jordan. He pursued a Master's of Instructional Technology at the University of Nebraska -Lincoln while working as the coordinator for the Student Technology Program on the UNL campus. Currently, Dr. Daher works as an Instructional Design Technology Coordinator for the college of engineering at the University of Nebraska - Lincoln leading the instructional design team at the College of Engineering. Dr. Daher collaborates with engineering faculty to document and research the integration of innovative instructional strategies and technologies in thier classroom. His latest collaborative submitted publication discusses use of interactive instructional videos in an engineering classroom.

\section{Dr. Lance C. Pérez, University of Nebraska, Lincoln}

Dr. Lance C. Pérez received his B.S. in Electrical Engineering from the University of Virginia, and his M.S. and Ph.D. in Electrical Engineering from the University of Notre Dame. He is currently a Professor of Electrical Engineering at the University of Nebraska-Lincoln where he directs the Perceptual Systems Research Group. His research interests include information, video and signal processing, engineered healthcare and engineering education. He was appointed interim dean of the College of Engineering in July 2016.

\section{Dr. Wayne A. Babchuk, University of Nebraska, Lincoln}

Wayne A. Babchuk is an Associate Professor of Practice in the Department of Educational Psychology (Quantitative, Qualitative, and Psychometrics Program), the Department of Anthropology, and the Department of Sociology at the University of Nebraska-Lincoln (UNL).. He also serves as Dean's Professor of Teaching and Learning for the College of Arts and Sciences Teaching Academy at UNL and as a Research Associate for the Kalahari Peoples Fund of southern Africa. As a research methodologist, he teaches and conducts research on the history, epistemology, application, and instruction of qualitative research across disciplines, research ethics, grounded theory, ethnography, grounded ethnography, and mixed methods. $\mathrm{He}$ is also involved in several other research tracks including faculty teaching and evaluation strategies, interdisciplinary collaboration, teaching applied anthropology, Kalahari San land and resource rights, research to practice links in minority health care, and student and instructor perceptions of the impact of social media on student success. With a broad and diverse background in both education and the social sciences, he strives to bring a holistic and interdisciplinary approach to all aspects of teaching, research, and service.

\section{Dr. Leilani A. Arthurs, University of Nebraska, Lincoln}

Dr. Arthurs holds a PhD in Civil Engineering \& Geological Sciences and has four years of formal graduate-level training in pedagogy. Her scholarly work over the past ten years focuses on STEM course transformation and STEM faculty professional development. She is currently an Assistant Professor in the Department of Earth \& Atmospheric Sciences at the University of Nebraska-Lincoln. 


\title{
Exploring Engineering Faculty Experiences with COPUS: Strategies for Improving Student Learning Dr. Tareq Daher, Dr. Wayne Babchuk, Dr. Lance Perez, Dr. Leilani Arthurs
}

\begin{abstract}
Few studies have examined engineering faculty use of observation protocols to evaluate teaching in the classroom including those that specifically focus on the Classroom Observation Protocol for Undergraduate STEM (COPUS). Toward this end, this ongoing pilot study explores engineering faculty's experiences utilizing the COPUS tool. Paired faculty teams trained in the use of COPUS conducted multiple peer observations of instructors teaching both undergraduate and graduate classes within the College of Engineering at a large Midwestern research intensive institution. Upon completion of the paired faculty classroom observations, researchers conducted focus group interviews with the faculty teams to solicit feedback on their use of the COPUS instrument. Faculty teams were then interviewed individually. Preliminary data analysis generated emergent categories pertaining to instructor and student behaviors as well as observer reflections useful for ascertaining the nature and extent of the use of student-centered teaching practices in the classroom, helped facilitate discussion of potentially effective pedagogical strategies, and considered ways in which both the COPUS training and instrument could be improved for future research.
\end{abstract}

\section{Introduction}

Peer-observation programs are increasingly utilized in engineering colleges with the goal of improving teaching practice in undergraduate and graduate education. A growing body of research on the Classroom Observation Protocol for Undergraduate STEM (COPUS) has demonstrated the potential of this tool for systematically documenting student and teacher behaviors as one means of assessing instructor effectiveness in STEM classrooms. Few studies, however, have focused specially on colleges of engineering or documented engineering instructor's experiences with the COPUS protocol. To better recognize engineering colleges' goals of improving student learning, assessing current use of research-based instructional practices, and enhancing faculty teaching practices, a pilot peer-observation program was implemented.

The program was developed and facilitated by an interdisciplinary team of researchers, staff, and faculty, led by the dean of the college. Six faculty observers and six instructors across five engineering departments volunteered to participate in the program. First, the observers completed the COPUS training. In teams of two, they observed 6 instructors for a total of 12 observations. Post observations, the observers provided feedback to the instructors and shared the results of their observational protocol. Faculty observers and instructors were interviewed by the researchers to gather their opinions on the protocol and survey interest and willingness to participate in future iterations of the program. Data gathered through the semi-structured interview protocol were analyzed by the research team. Preliminary findings of the study are presented in this paper.

Keywords: Teaching Evaluation, Active Learning, Faculty experiences, COPUS, Student learning, Faculty Development 


\section{The Use of Peer-Observation Protocols in STEM Education}

Classroom observation instruments provide a structure for peer-observation of teaching. Similar to end-of-term student course evaluations, peer observation data can play a critical role in providing faculty with feedback on their teaching methods, communication, active learning techniques, and student engagement. Furthermore, observation data can provide a basis for informed critical self-reflection that may prompt positive changes not only at the instructor level but also at departmental, college and institutional levels (Smith, Jones, Gilbert, \& Wieman (2013). Although not the specific focus of this research, these data can also serve as another means of assessing the teaching component of faculty as part of their annual review and/or promotional evaluation.

Several peer observation protocols are available for evaluating teaching at universities. Validated observation protocols can be used to supply faculty with feedback on their teaching and their students' in-class behaviors. Additionally, they provide faculty with observation data that can be utilized for continuous improvement of teaching and to improve student learning outcomes. There are a number of validated classroom observation protocols that are commonly referred to in the literature. For example, the Teaching Dimensions Observation Protocol (TDOP) captures nuances of teaching behaviors in a descriptive manner (Hora, Oleson, \& Ferrare, 2013). The TDOP was developed as part of an NSF funded study. Through six categories on teaching methods, observers apply a code and take notes in 2-minute intervals. In STEM classrooms, two observational protocols are commonly used: the Reformed Teaching Observation Protocol (RTOP) and the Classroom Observation Protocol for Undergraduate STEM (COPUS).

The Reformed Teaching Observation Protocol (RTOP) was developed by the Evaluation Facilitation Group of the Arizona Collaborative for Excellence in the Preparation of Teachers (Sawada, Piburn, Judson, Turley, Falconer, Benford, \& Bloom, 2002). RTOP employs 25 items that are evaluated on a Likert scale. Each item connects a teaching practice and the scope of which it was used in the classroom. One major disadvantage of RTOP is its need for substantial training over the course of multiple days.

Smith, et. al. (2013) state that RTOPs' substantial training and TDOP's lengthy categories were reasons for developing a newer protocol that requires less training. As a result, they developed a peer-observation instrument and process that aims to collect information about Science, Technology, Engineering, and Mathematics (STEM) teaching practices. In their 2013 study, they introduced the Classroom Observation Protocol for Undergraduate STEM (COPUS). The protocol is a tool that can provide feedback to instructors while characterizing student behaviors in the classroom. It also provides the means to determine faculty professional development needs. COPUS employs the 2-minute coding concept introduced in the TDOP protocol with a shorter (1.5 hour) training for observers. Observers identify and record student and instructor behaviors from a list of 25 codes within a 2 -minute period.

When reviewing the literature on the use of classroom-observation protocols, we find lengthy discussions on the usability and validity of the aforementioned protocols (Hora et al. 2013; Sawada et al. 2002; Smith et al.2013), examples and discussions of the application of the protocols (Amrein-Beardsley, Popp, 2012; Hora \& Ferrare, 2013), and examinations of the 
context in which undergraduate teaching is evaluated (Wieman, 2015). However, there is little discussion on the engineering faculty experiences and perceptions on the use of observation protocols, more specifically, the use of COPUS for teaching evaluation. In this study, we contribute to the literature by providing insight into the engineering faculty observers' experiences and perceptions. For the purposes of this study, the research team chose to use the COPUS for a pilot study about the evaluation of teaching in the college of engineering at a Midwestern tier-one research institution. The goals of the pilot study include (a) characterize faculty observers' experiences making classroom observations an providing peer feedback using the COPUS (b) describe instructors' perspectives on being observed and receiving peer feedback with the COPUS, and (c) determine how to effectively transform the evaluation of teaching in the college of engineering by fostering a culture of peer-observation extending beyond the bounds of this pilot study.

\section{Methodology}

\section{The Research Team}

Under direction of the Dean of the College of Engineering, a multidisciplinary team was assembled to lead and assess the teaching evaluation pilot. The team included the Dean of the College of Engineering, an Associate Professor in the College of Education and Human Sciences who specializes in research design and implementation, a discipline-based education researcher from a STEM field in College of Arts and Sciences, and the Instructional Design Technology Coordinator for the College of Engineering.

\section{Sample Selection Procedures and Participant Training}

The Dean collaborated with the department chairs to recruit six associate and full professors to serve as peer observers. These peer observers have extensive teaching experience, use active learning strategies in their own classrooms, and are the recipient of teaching awards. They are known in their departments for leading teaching and learning efforts, with some also involved in the scholarship of teaching and learning in engineering education. Similarly, the Dean and the department chairs recruited six-faculty instructors to be observed. Both observers and instructors volunteered to participate in the pilot study.

The six peer observers were affiliated with the Department of Mechanical Engineering $(n=2)$, Department of Civil Engineering ( $n=2)$, Department of Chemical and Biomolecular Engineering $(\mathrm{n}=1$, and Department of Electrical and Computer Engineering $(\mathrm{n}=1)$. Of these, three were associate professors and three were full professors. Four were males and two were females and all had served in their present positons for over ten years. None had prior experience using the COPUS tool. The instructors who were observed were affiliated with the departments of Civil Engineering, Electrical Engineering, Mechanical and Materials Engineering, and Chemical and Biomolecular Engineering.

After peer observers and instructors were recruited, this study's team planned two separate meetings. The first meeting included members of the study team and the peer observers and was aimed at training the peer observers to use the COPUS. The second meeting included members 
of this study's team and the instructors and was aimed at providing an overview of the next steps, discussing time commitments, and answering instructors' questions.

Two members of the research team facilitated a COPUS training session for the six peer observers. The COPUS training followed the guidelines provided Smith et al. (2013). The duration of the training was 1.5 hours divided into 8 stages. It began with introductions and a brief rationale for the exercise, the protocol and codes were reviewed and discussed as a group followed by several guided practice exercises. During the exercises, faculty were presented with videos of lectures that represented a variety of teaching methods. They began with individually marking the protocol, then marked in pairs, and then discussed their codes as a group. The final activity included establishing a way for the protocols to be gathered.

After the COPUS training for peer observers was complete, the research team communicated to the instructors the names of their observers. Each instructor was observed twice by a pair of peer observers. Each pair of observers observed two instructors twice (i.e., four observations per observing team). In total, the three observation teams conducted twelve observations. Each observation occurred for the duration of a 50-minute class session. After the observations, the research team collected the peer observers completed protocols for analysis.

\section{Data Collection and Analysis}

An instrumental case study design (Baxter \& Jack, 2008; Creswell \& Poth, 2018; Merriam \& Tisdell, 2016; Stake, 1995; Yin, 2014) was employed to incorporate an in-depth analysis of a "bounded system" (i.e., the College of Engineering at a large Midwestern research-intensive institution). Case study demands multiple forms of data collection to glean an in-depth analysis of the selected case. Two-tier sampling in case study design requires first, the selection of the case (the College of Engineering) and second, sites (the individual departments) and participants (faculty members) in the study (discussed above). Along these lines, the COPUS instrument employs quantitative and qualitative measures to assess classroom interactions and, therefore, we have begun to analyze both forms of data. Validation strategies involved triangulation via multiple data sources (interviews, documents), multiple researchers, maximum variation sampling, member checking, and peer review (Babchuk, Guetterman, \& Garrett, 2017; Creswell \& Miller, 2000; Creswell \& Poth, 2018; Marshall \& Rossman, 2016; Merriam \& Tisdell, 2016; Tracy, 2010).

Two members of our research team interviewed each peer-observing team as a focus group in the second phase of our research. We are currently in the process of scheduling instructor interviews. A semi-structured interview was designed by the research team consisting of 12 open-ended questions and several probes. The observer protocol asked the observers to describe their interest in participating in the pilot study, their experiences serving as observers, challenges, understanding of college teaching and learning goals, and opportunities for improvement. Observer interviews lasted approximately 30-45 minutes each and participants provided their consent for the interviews to be recorded. Following observer interviews, all interviews were transcribed and data analysis was undertaken. Findings were reviewed by other members of our research team (peer review) and then will be provided to participants (member checking) for their input. 


\section{Preliminary Findings and Discussion}

This pilot study focuses on exploring engineering faculty experiences and perceptions utilizing the Classroom Observation Protocol for Undergraduate STEM (COPUS) as part of larger longterm project aimed at improving teaching and learning in the College of Engineering at our host institution. The current project can be viewed as consisting of four phases. The first phase involved the assembly of our research team and our collaborative project design and selection of a case study methodology to study a bounded system (i.e., teaching and learning in the College of Engineering). Participants were selected employing purposeful criterion-based maximum variation sampling within the College to serve as peer observers or instructors. Both groups (observers and instructors) attended orientation sessions and peer observers were also trained to use the COPUS protocol. In phase two, peer-observers were interviewed by members of our research team to elicit their perceptions and experiences using the COPUS protocol. Data analysis revealed emergent categories and themes focusing on observer assessments of instructor strategies and learner behaviors of the classrooms they observed, their own self-reflections on teaching strategies they (observers) employed, the ways in which they believed the instructors and their own teaching strategies fit their understanding of the College's teaching and learning goals, and their feedback on the potential strengths and limitations of the COPUS protocol (Table 1).

As illustrated, reasons given by peer-observers for participation in our COPUS study was their desire to improve their own instruction, to better facilitate conversations about teaching with their colleagues, to learn more about teaching effectiveness they could apply in their own classrooms, and fulfill requests made by the Dean. Strengths of utilizing the COPUS tool identified by peer-observers included that they felt in many ways it was effective to assess teaching and learning strategies particularly for smaller enrollment classes and for undergraduate classes for which it was originally designed. They believed that participating in the study (i.e., utilizing COPUS) provides ideas for teaching self-reflection, encourages the use of active learning strategies through peer observation, encourages conversation about teaching among faculty members, motivates participants to be better teachers by observing others, and provides opportunities for mentoring peers. Another strength of the COPUS instrument was participants' felt its use in many ways aligned with the College's teaching goals. They believed use of the COPUS tool was consistent with the College's emphasis on active teaching and learning strategies, encourages innovative teaching strategies, discussion, and raising critical questions about teaching, and helps create awareness of these goals among faculty. Conversely, it was reported that goals of the College continue to shift and they have their own individual goals that may or may not be consistent with those of the College.

Challenges of the COPUS tool were that participants believed different categories were needed (or missing) to better capture all classroom behaviors, there was too much emphasis (on the form) on the use of clickers, they needed more opportunity for comments (on the form), it doesn't work as well for larger enrollment classes or for lab-based classes, is ineffective for project-based work, and doesn't capture all types of learning. Peer-observers also critiqued the COPUS training they received suggesting they could have benefitted from a shorter training video, could have used more practice before engaging in the formal observations, and could have been provided more feedback as part of the training prior to the observations. Challenges in the 
utilization of COPUS (i.e., participating in the pilot study) included that the purpose of using COPUS needs to be better communicated at the onset of the study, it took time to become proficient with COPUS, it could be threatening to participants in terms of what the data will be used for (i.e., regarding teacher evaluation and promotional aspects), and instructors being observed could benefit from feedback after observations. Participants commented that it was hard to write reflections/comments as they were coding instructor and student behaviors and that these reflections/comments could help enrich the quality of the data.

The research team is currently moving into phase three of this research involving team-based interviews with the instructors to elicit their feedback on the COPUS protocol and their participation in this project. Phase four of this pilot study will consist of refining our findings based on our joint analysis of data and further input from the participants (both observers and instructors). Findings from this pilot study will serve as the basis for the design and implementation of a larger and more in-depth research project ultimately aimed at improving teaching and learning within the College of Engineering.

Peer-observation programs targeted at improving teaching practice and student learning are becoming increasingly popular across disciplines as research institutions strive to improve the teaching component of their institution's mission. Within STEM education, the Classroom Observation Protocol for Undergraduate STEM (COPUS) has demonstrated potential to be successful at systematically documenting student and teacher behaviors in the classroom. Few studies to date have focused specifically on the potential effectiveness of the COPUS instrument within engineering classrooms. As has become clear, we believe COPUS, the Teaching Practices Inventory, and other tools for measuring and improving instructional teaching practices can and should be employed to better realize our shared goals of offering a better education to today's engineering students.

Table 1. Peer Observer Interview Preliminary Data Analysis

\begin{tabular}{|c|c|c|}
\hline \multicolumn{3}{|c|}{ Themes } \\
\hline $\begin{array}{l}\text { Reasons for Participation in } \\
\text { COPUS Study }\end{array}$ & Strengths of COPUS & $\begin{array}{l}\text { Challenges/Opportunities of } \\
\text { COPUS }\end{array}$ \\
\hline $\begin{array}{l}\text { Improve own instruction } \\
\text { Facilitate conversations about } \\
\text { teaching } \\
\text { Learn more about teaching } \\
\text { effectiveness } \\
\text { Volunteered by Dean }\end{array}$ & $\begin{array}{l}\text { The COPUS Tool } \\
\text { Focuses on teaching and } \\
\text { learning } \\
\text { Good for smaller classes } \\
\text { Good for undergraduate classes }\end{array}$ & $\begin{array}{l}\text { The COPUS Tool } \\
\text { Different categories needed } \\
\text { Too much on form on clickers } \\
\text { (bias toward clickers) } \\
\text { Need more opportunity for } \\
\text { comments (on the form) } \\
\text { Doesn't work for big classes } \\
\text { Doesn't work for lab classes } \\
\text { Doesn't encourage project } \\
\text { based work } \\
\text { Doesn't capture all types of } \\
\text { learning } \\
\text { Took time to be proficient }\end{array}$ \\
\hline & $\begin{array}{l}\text { COPUS Utilization } \\
\text { (Participation) }\end{array}$ & $\begin{array}{l}\text { COPUS Training } \\
\text { Shorter training video } \\
\text { More practice needed }\end{array}$ \\
\hline
\end{tabular}




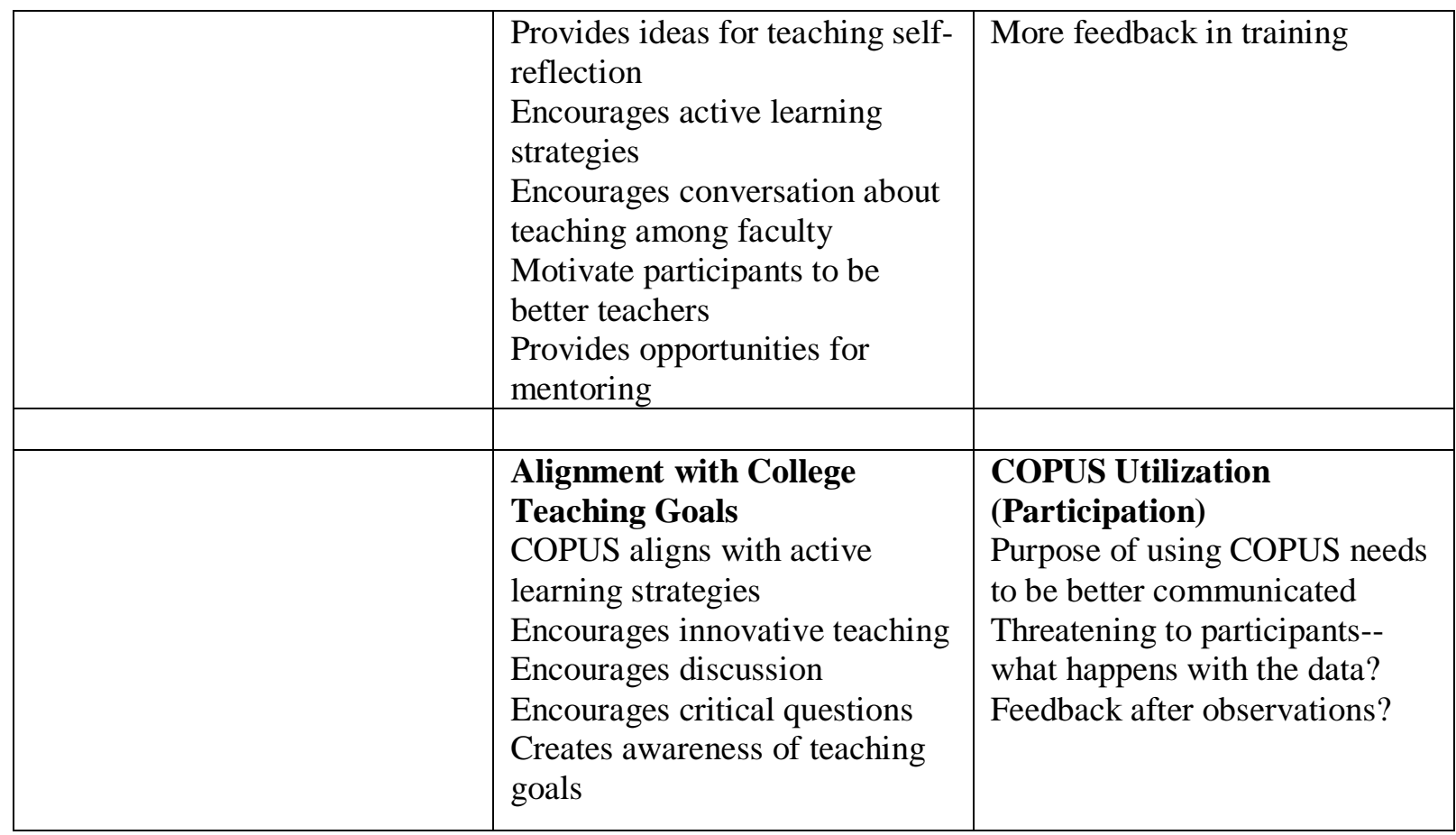

\section{References Cited}

Amrein-Beardsley, A., \& Popp, S. E. O. (2012). Peer observations among faculty in a college of education: investigating the summative and formative uses of the Reformed Teaching Observation Protocol (RTOP). Educational Assessment, Evaluation and Accountability, 24(1), 524.

Babchuk, W.A., Guetterman, T.C., \& Garrett, A.L. (2017). A horse of a different color: Establishing validity and reliability in qualitative research. Proceedings of the $36^{\text {st }}$ Annual Research-to-Practice Conference in Adult and Higher Education. University of Central Oklahoma. Memphis, Tennessee.

Baxter, P., \& Jack, S. (2008). Qualitative case study methodology: Study design and implementation for novice researchers. The Qualitative Report, 13(4): 544-559.

Charmaz, K. (2014). Constructing grounded theory: A practical guide through qualitative analysis ( $2^{\text {nd }}$ ed.). London: Sage.

Creswell, J.W., \& Miller, D.L. (2000). Determining validity in qualitative research. Theory Into Practice, 39, 124-130.

Creswell, J. W., \& Poth, C.N. (2018). Qualitative inquiry and research design: Choosing among five approaches $\left(4^{\text {th }} \mathrm{ed}\right.$.). Thousand Oaks, CA: Sage. 
Hora, M. T. (2013). Exploring the use of the Teaching Dimensions Observation Protocol to develop fine-grained measures of interactive teaching in undergraduate science classrooms. Wisconsin Center for Education Working Paper, 6.

Hora, M. T., \& Ferrare, J. J. (2013). Instructional systems of practice: A multidimensional analysis of math and science undergraduate course planning and classroom teaching. Journal of the Learning Sciences, 22(2), 212-257.

Hora, M. T., Oleson, A., \& Ferrare, J. J. (2013). Teaching dimensions observation protocol (TDOP) user's manual. Madison: Wisconsin Center for Education Research.

Marshall, C., \& Rossman, G.B. (2016). Designing qualitative research (6 ${ }^{\text {th }}$ ed.). Thousand Oaks, CA; Sage.

Smith, M. K., Jones, F. H., Gilbert, S. L., \& Wieman, C. E. (2013). The Classroom Observation Protocol for Undergraduate STEM (COPUS): a new instrument to characterize university STEM classroom practices. CBE-Life Sciences Education, 12(4), 618-627.

Sawada, D., Piburn, M. D., Judson, E., Turley, J., Falconer, K., Benford, R., \& Bloom, I. (2002). Measuring reform practices in science and mathematics classrooms: The reformed teaching observation protocol. School science and mathematics, 102(6), 245-253.

Stake, R. (1995). The art of case study research. Thousand Oaks, CA: Sage

Tracy, S.J. (2010). Qualitative quality: Eight "big-tent" criteria for excellent qualitative research. Qualitative Inquiry, 16(1), 837-851.

Wieman, C. (2015). A better way to evaluate undergraduate teaching. Change: The magazine of higher learning, 47(1), 6-15.

Yin, R. K. (2014). Case study research: Design and methods (5t $\mathrm{t}^{\mathrm{h}}$ ed.). Thousand Oaks, CA: Sage.

\section{Biographical Information}

\section{Tareq Daher}

Tareq Daher earned his Bachelors in Computer Science from Mutah University in Jordan. He pursued a Master's of Instructional Technology at the University of Nebraska -Lincoln (UNL) while working as the coordinator for the Student Technology Program on the UNL campus. Dr. Daher worked as an Instructional Design Technology Coordinator for the Office of Online and Distance Education at the University of Nebraska - Lincoln leading the instructional design team at the College of Engineering. Currently, Dr. Daher works for the Deans' office leading teaching and learning and faculty development efforts. He collaborates with engineering faculty to document and research the integration of innovative instructional strategies and technologies in their classrooms. 


\section{Wayne Babchuk}

Wayne A. Babchuk is an Associate Professor of Practice in the Department of Educational Psychology (Quantitative, Qualitative, and Psychometrics Program), the Department of Anthropology, and the Department of Sociology at the University of Nebraska-Lincoln (UNL). As a research methodologist, he teaches and conducts research on the history, epistemology, application, and instruction of qualitative research across disciplines, research ethics, grounded theory, ethnography, grounded ethnography, and mixed methods.

\section{Lance Pérez}

Dr. Lance C. Pérez received his B.S. in Electrical Engineering from the University of Virginia, and his M.S. and Ph.D. in Electrical Engineering from the University of Notre Dame. He is currently the Omar H. Heins Professor of Electrical and Computer Engineering at the University of Nebraska-Lincoln where he directs the Perceptual Systems Research Group. His research interests include information, video and signal processing, engineered healthcare and engineering education. He was appointed interim dean of the College of Engineering in July 2016.

\section{Leilani Arthurs}

Dr. Arthurs holds a PhD in Civil Engineering \& Geological Sciences and has four years of formal graduate-level training in pedagogy. Her scholarly work over the past ten years focuses on STEM course transformation and STEM faculty professional development. She is currently an Assistant Professor in the Department of Earth \& Atmospheric Sciences at the University of Nebraska-Lincoln. 